\title{
Influence of surface morphology on the very high cycle fatigue behavior of metastable and stable austenitic $\mathrm{Cr}$-Ni steels
}

\author{
Annika Boemke ${ }^{1, *}$, Marek Smaga ${ }^{1}$, and Tilmann Beck $^{1}$ \\ ${ }^{1}$ Institute of Materials Science and Engineering, TUK, 67663 Kaiserslautern, Germany
}

\begin{abstract}
The present study investigates conventional and cryogenically turned specimens of metastable austenitic steel AISI 347 and stable austenitic steel AISI 904L in the VHCF regime. The cryogenic turning process includes cooling by $\mathrm{CO}_{2}$ snow and generates a surface layer on the specimens of metastable austenitic steel, which is characterized by a phase transformation from paramagnetic fcc-austenite to ferromagnetic bcc-martensite and grain refinement. The stable austenitic steel retains its purely austenitic structure after cryogenic turning, but also shows grain refinement in the surface layer. The specimens with different surface morphology were cyclically loaded at ambient temperature using an ultrasonic fatigue testing system developed and built at the authors' institute. The testing machine operates at frequencies of approx. $20 \mathrm{kHz}$ to achieve high numbers of load cycles within a reasonable time. To avoid self heating of the specimen, the tests were performed in pulse-pause mode. All specimens were tested with a load ratio of $R=-1$. During cyclic loading, the metastable austenitic steel partially transformed from paramagnetic fcc-austenite to ferromagnetic bcc-martensite, while no phase transformation could be detected in the stable austenitic steel.
\end{abstract}

\section{Introduction}

Investigations in the very high cycle fatigue (VHCF) regime on steels are necessary to characterize fatigue behavior above $10^{7}$ load cycles [1]. Metallic materials can be classified into two different types in the VHCF regime: i) type I materials, which are ductile singlephase materials without inner defects and ii) type II materials, which have inner defects such as inclusions [2]. Type I materials show predominant crack initiation from the surface whereas crack initiation in type II materials changes from surface to subsurface cracks in the VHCF regime, often characterized by a typical fisheye structure.

In type I materials, which have a mostly fcc structure, an increasing surface roughness occurs during fatigue loading due to cyclic slip irreversibilities. In a further state, persistent slip bands (PSB) can be formed at the surface, if the PSB threshold is exceeded, and can lead to a crack initiation at the surface [3]. This effect shows that the influence of the surface plays a significant role in fatigue behavior even in the VHCF regime.

Until now the influence of surface modification has been investigated up to the high cycle fatigue regime [4-8]. Especially in metastable austenitic steels the effect of transformation from fcc - austenite to bcc - martensite is used to generate martensitic surface layers, e.g. with shot peening or deep rolling $[9,10]$. A positive influence of cryogenic turning on the lifetime of metastable austenitic steel is determined as well [5]. Subsequent polishing of the cryogenically turned specimen to eliminate the influence of roughness induced by the cryogenic turning process further increases fatigue life of the specimen [4]. So far, the influence of cryogenic turning has not been investigated in the VHCF regime. Many investigations focus on the VHCF behavior of austenitic stainless steels [11-13]. Stable austenitic steels also show failure above $10^{8}$ load cycles [14]. Metastable austenitic steels show a true fatigue limit in the VHCF regime, if bccmartensite is developed during fatigue testing [15]. Some investigations focus on predeformed metastable austenites containing bcc-martensite before testing. Predeformed specimens with bcc - martensite content of 27 vol \% show a true fatigue limit as well, whereas predeformed specimens with bcc - martensite content of $54 \mathrm{vol} \%$ show a second decrease in the Wöhler-curve in the VHCF regime [16].

To investigate the influence of surface layers on the VHCF behavior of austenitic steels, this study focused on VHCF tests of stable and metastable austenitic steels with an ultrasonic testing system up to $\mathrm{N}=1 \times 10^{9}$. The surface morphology is generated by the cryogenic turning process, which induces bcc-martensite in the surface layer.

\section{Materials and experimental setup}

\subsection{Materials}

The investigated materials were the metastable austenitic steel AISI 347 (X6CrNiNb1810, solution-annealed $\mathrm{T}=1050{ }^{\circ} \mathrm{C}, \mathrm{t}=35 \mathrm{~min}$, quenched in $\mathrm{He}$ ) and the stable 
austenitic steel AISI 904L (X1NiCrMoCu25205, solution-annealed $\mathrm{T}=1100{ }^{\circ} \mathrm{C}, \mathrm{t}=30 \mathrm{~min}$, quenched in $\mathrm{H}_{2} \mathrm{O}$ ). The chemical compositions are given in table 1 .

Table 1. Chemical composition of AISI 347 and AISI 904L in wt \%

\begin{tabular}{|c|c|c|c|c|c|c|c|}
\hline & $\mathbf{C}$ & $\mathbf{N}$ & $\mathbf{C r}$ & $\mathbf{N i}$ & $\mathbf{M o}$ & $\mathbf{C u}$ & $\mathbf{M n}$ \\
\hline $904 \mathrm{~L}$ & 0.03 & 0.06 & 19.92 & 24.34 & 4.22 & 1.42 & 0.95 \\
\hline 347 & 0.02 & 0.02 & 17.19 & 9.44 & 0.23 & 0.11 & 1.55 \\
\hline
\end{tabular}

The metastability of both materials is characterized by $\mathrm{M}_{\mathrm{d} 30}$ temperature according to Angel [17] as well as martensite start temperature $\mathrm{M}_{\mathrm{S}}$ according to Eichelmann [18]. The characteristic temperatures as well as mechanical properties of both materials are given in table 2 and confirm the metastability of AISI 347 and the high stability of AISI 904L. Both materials consist of a pure austenitic microstructure at initial state. The average grain size equivalent diameter is $17 \mu \mathrm{m}$ for AISI 347 and $38 \mu \mathrm{m}$ for AISI 904L including twins.

Table 2. Characteristic temperatures and mechanical properties of both materials

\begin{tabular}{|c|c|c|c|c|c|}
\hline & $\begin{array}{l}\mathbf{M}_{\mathbf{d 3 0} \text {,Angel }} \\
\quad \text { in }{ }^{\circ} \mathrm{C}\end{array}$ & $\begin{array}{l}\mathbf{M}_{\text {S,Eichelmann }} \\
\quad \text { in }{ }^{\circ} \mathbf{C}\end{array}$ & $\begin{array}{c}\text { Young's } \\
\text { modulus } \\
\text { in MPa }\end{array}$ & $\begin{array}{c}\mathbf{R}_{\mathrm{p} 0.2} \\
\text { in } \\
\text { MPa }\end{array}$ & $\begin{array}{c}\text { UTS in } \\
\text { MPa }\end{array}$ \\
\hline $904 \mathrm{~L}$ & -220 & -1156 & 187 & 307 & 631 \\
\hline 347 & 46 & -87 & 179 & 225 & 603 \\
\hline
\end{tabular}

Grain orientation maps determined by electron backscatter diffraction (EBSD) at initial state of both materials are shown in Fig. 1. Both materials do not have a preferred orientation.

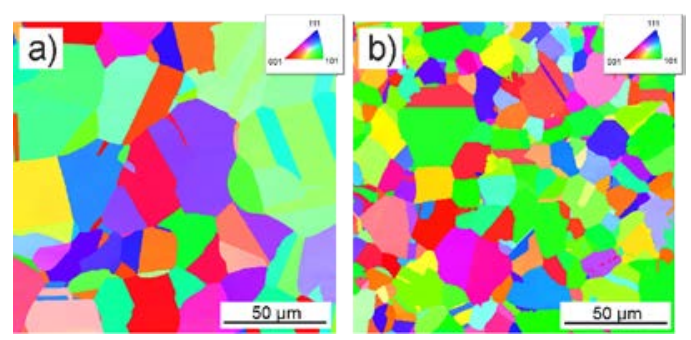

Fig. 1. Grain orientation of AISI 904L (a) and AISI 347 (b) at solution-annealed state

\subsection{Experimental setup}

The fatigue tests were performed at an ultrasonic VHCF testing system built at the authors' institute (Fig. 2). The testing system consists of an ultrasonic generator, which generates frequencies in the range of $\mathrm{f}=19.5$ to $20.5 \mathrm{kHz}$. Electrical oscillation is transformed to a mechanical oscillation by a converter using piezoceramic elements with an attached booster to increase the mechanical vibration amplitude. The specimen is fixed at the booster on one side. The testing setup is controlled by a Windows based computer and a
LabVIEW based real time system. The systems are also used for data collection during fatigue testing.

The VHCF testing system features a Compact Laser Vibrometer to measure the displacement amplitude (displ.a) of the lower end of specimen. Using a multifunction I/O device with a sample rate of $500 \mathrm{kS} / \mathrm{s}$ it is possible to resolve the sinusoidal oscillation of $20 \mathrm{kHz}$. Software developed at the authors' institute, based on LabView, counts the real number of cycles. The software also acquires the frequency of the oscillation of the specimen. An infrared sensor measures the temperature of the gauge length of the specimen. The difference between the maximum temperature and the start temperature before pulsing is calculated as change in temperature $\Delta \mathrm{T}$ (see Fig. 6). To avoid overheating the specimens, all tests were performed in pulse-pause mode, depending on the stress level. Three compressed air coolers were also applied around the specimen.
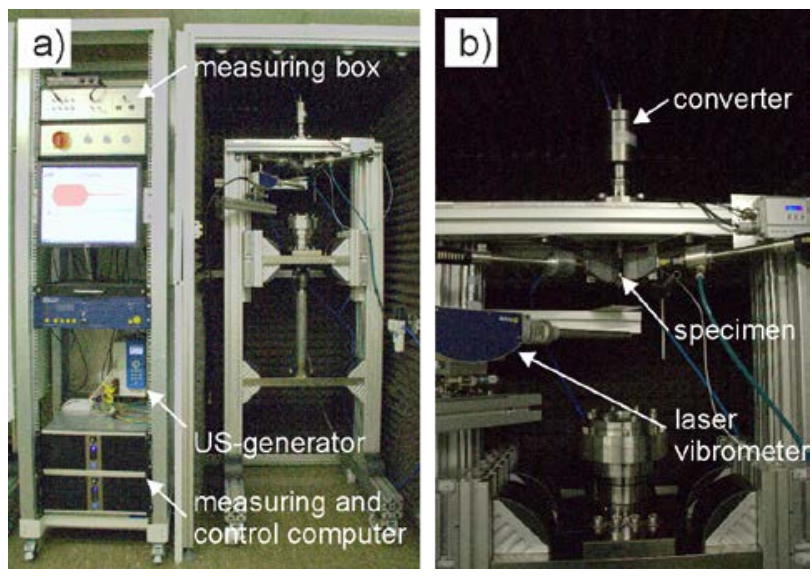

Fig. 2. VHCF testing system including US generator, measuring computers and measuring box (a) and close up view (b) of installed specimen with measuring equipment

The geometry of the specimen was designed with the finite element method (FEM) program ABAQUS using the mechanical properties of each material to ensure the eigenfrequency of the specimen was in the range of the working frequency of the ultrasonic generator. Thus the specimen oscillated symmetrically with the maximum of displacement at both ends and the stress maximum in the gauge length. The stress amplitude was calculated with FEM based on the elastic properties of the material and the displacement amplitude measured by laser vibrometer. Due to the high passive forces of the cryogenic turning process [19] the diameter of the gauge length may not be less than $4 \mathrm{~mm}$. The geometry of the specimen is given in figure 3 . 
a)

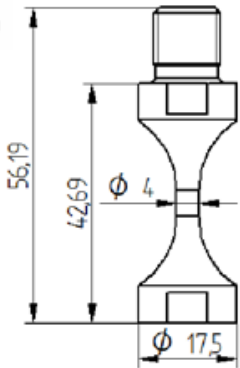

b)

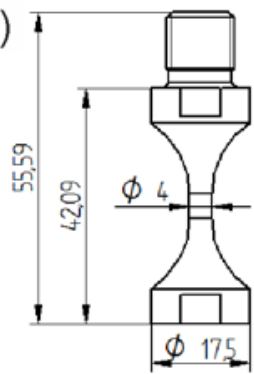

Fig. 3. Specimen geometry of AISI 904L (a) and AISI 347 (b)

To measure bcc-martensite in the material a Feritscope $^{\mathrm{TM}}$ sensor was used. This sensor detects ferromagnetic parts in the specimen. The values are given in $\mathrm{Fe} \%$ and can be converted in vol \% of $\alpha^{\prime}$ martensite by a calibration factor [20]. In this study the values in $\mathrm{Fe} \%$ were used.

\section{Results}

\subsection{Influence of cryogenic turning on surface morphology}

To investigate the influence of surface morphology on VHCF behavior, four surface morphologies were produced. For reference, conventionally turned and subsequently mechanically polished specimens were tested. The specimens of metastable austenite AISI 347 were additionally electrolytically polished to eliminate the remnant bcc-martensitic content of $0.2 \mathrm{Fe} \%$ induced on the surface in the production process. After electrolytic polishing, no ferromagnetic phases were detected. Hence, AISI 904L specimen consisted of a stable austenitic surface layer after polishing $\left(\mathrm{SSL}_{\mathrm{p}}\right)$ while AISI 347 specimen consisted of an austenitic surface layer after polishing $\left(\mathrm{ASL}_{\mathrm{p}}\right)$. To produce further morphologies, a cryogenic turning process was used. Two $\mathrm{CO}_{2}$ nozzles were attached to the $\mathrm{CNC}$ lathe to cool the specimens' surface during turning. The following turning parameters were used: cutting depth $\mathrm{a}_{\mathrm{p}}=0.2 \mathrm{~mm}$, feed $\mathrm{f}=0.35 \mathrm{~mm} / \mathrm{rev}$, cutting speed $\mathrm{v}_{\mathrm{c}}=30 \mathrm{~m} / \mathrm{min}$ [21]. The cryogenically turned specimens were labelled as follows: $\mathrm{SSL}_{\mathrm{t} 035}$ for the stable surface layer after cryogenic turning of AISI $904 \mathrm{~L}$, and $\mathrm{MSL}_{\mathrm{t} 035}$ for the martensitic surface layer after turning of AISI 347.

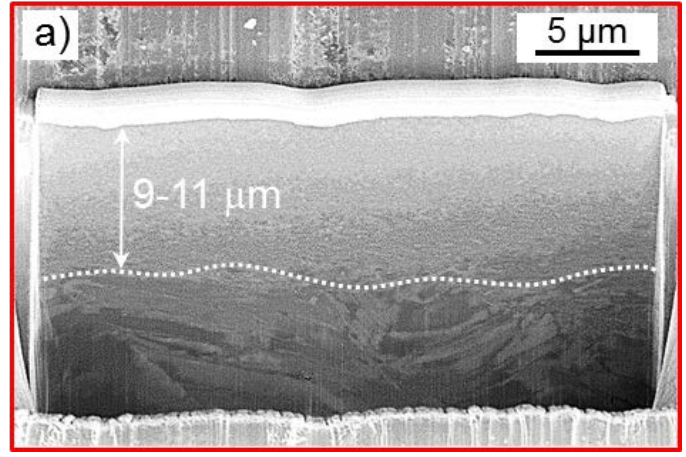

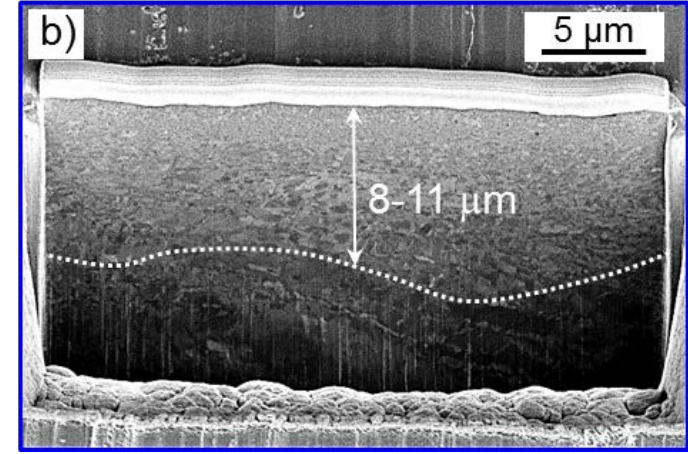

Fig. 4. Focused Ion Beam cuts of cryogenically turned surfaces of AISI 904L (a) and AISI 347 (b)

The surface layers of the cryogenically turned specimens were characterized using focused ion beam (FIB) microscopy. Figure 4 shows micrographs of FIB cuts up to a depth of about $20 \mu \mathrm{m}$ for both materials with near surface microstructure acquired by detecting secondary electrons resolved by the ion beam. AISI 904L as well as AISI 347 show a nanocrystalline layer directly beneath the surface. The depth of the layer for both materials is up to $11 \mu \mathrm{m}$.

The metastable austenitic steel AISI 347 partially transformed from paramagnetic fcc $\gamma$-austenite to deformation induced ferromagnetic bcc $\alpha^{\prime}$-martensite. Measurements by a Feritscope ${ }^{\mathrm{TM}}$ sensor, which detects ferromagnetic phases in the specimen, confirmed the presence of bcc-martensite. The stable austenite AISI 904L maintained its austenitic structure, which was also confirmed by Feritscope ${ }^{\mathrm{TM}}$ measurements.

The topography of the specimens with different morphologies was characterized by confocal microscopy (Fig. 5) using the software $\mu$ Soft control. The analysis was performed with the software MountainsMap Premium. The average roughness $\mathrm{R}_{\mathrm{z}}$ was for the polished specimens $\left(\mathrm{SSL}_{\mathrm{p}}, \mathrm{ASL}_{\mathrm{p}}\right)$ very low $\left(\mathrm{R}_{\mathrm{z}}<1 \mu \mathrm{m}\right)$ but higher for the cryogenically turned specimens $\left(\mathrm{MSL}_{\mathrm{t} 035}\right.$, $\mathrm{SSL}_{\mathrm{t} 035}$ ), approximately $\mathrm{R}_{\mathrm{z}}=11 \mu \mathrm{m}$. a)
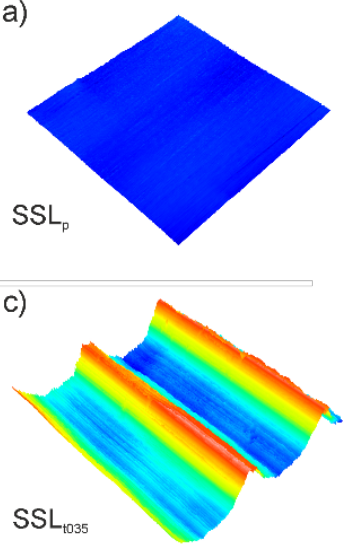

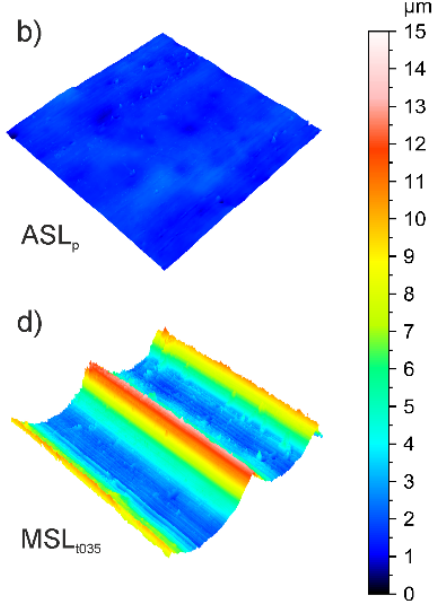

Fig. 5. Surface topography of AISI 904L in $\mathrm{SSL}_{p}$ (a) and $\mathrm{SSL}_{\mathrm{t} 035}$ state (c) and AISI 347 in $\mathrm{ASL}_{\mathrm{p}}$ (b) and $\mathrm{MSL}_{\mathrm{t} 035}$ state (d) by confocal microscopy 


\subsection{VHCF results of the conventionally turned specimens}

To investigate the influence of surface morphology on the very high cycle fatigue behavior of metastable and stable austenitic $\mathrm{Cr}-\mathrm{Ni}$ steels, the polished specimens from both materials were firstly tested at the ultrasonic testing system. The Feritscope ${ }^{\mathrm{TM}}$ measurements indicated $0.00 \mathrm{Fe} \%$ in both specimens before testing.

Both materials showed strong self heating during the load pulses. Even after finishing the pulse, further surface heating could be detected with the infrared pyrometer (Fig. 6). The change of temperature $\Delta \mathrm{T}$ during a pulse was calculated as the difference between the maximum temperature and the temperature at the start of each pulse. The higher the displacement amplitude, the higher the self heating of the gauge length. Therefore, the pulse-pause ratio had to be adjusted for each displacement level. All cycles above $90 \%$ of the target amplitude were counted and considered in the evaluation of fatigue life.

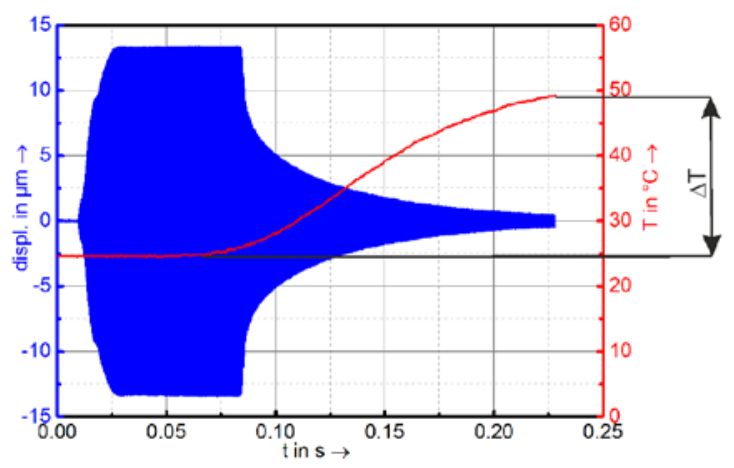

Fig. 6. Displacement and temperature of AISI 904L during pulse

The oscillation behavior of AISI 904L differed from that of AISI 347 due to the high austenite stability of AISI 904L, i.e. the displacement amplitude of AISI 904L increased only slightly during testing as shown in figure 7 for a single step test compared to AISI 347 (Fig. 8).

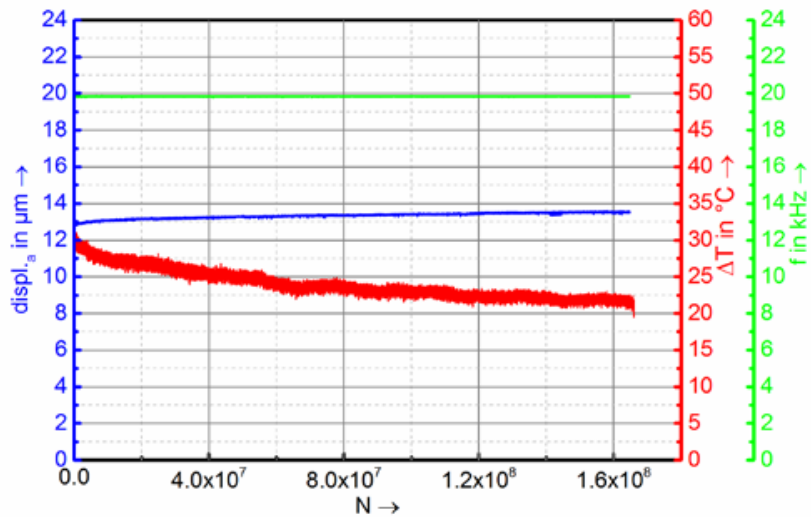

Fig. 7. Displacement amplitude, temperature difference and frequency of AISI 904L during testing at $\sigma_{\mathrm{a}}=315 \mathrm{MPa}$

Due to cyclic hardening, the temperature difference decreased. The decrease flattened during testing and temperature reached a nearly constant level up from $1 \times 10^{8}$ cycles until specimen failure. The changes in temperature and the increase of displacement amplitude were less pronounced than for AISI 347. For the calculation of the stress amplitude in the gauge length the average value of displacement amplitude $(13.4 \mu \mathrm{m})$ at $1 \times 10^{7}$ cycles was used. The frequency of the oscillation measured with the laser vibrometer was constant during the whole test.

The AISI 347 specimen also showed strong self heating during the load pulses. Even after finishing the pulse further surface heating could be detected, similar to AISI 904L (comp. Fig 6). Accordingly, the pulse time had to be reduced to $40 \mathrm{~ms}$ and the pause time extended up to $10 \mathrm{~s}$. During the test, the oscillation of the specimen changed to higher amplitudes despite constant control voltage for generating the oscillation. The first pulses were characterized by an oscillation plateau with a constant amplitude level during each pulse as shown in figure 8a). The target amplitude is marked with a red colored dashed line. During further cycling, this plateau shape changed to pulses with an increasing displacement level above the target amplitude due to the transient behavior of the material (Fig. 8b). Readjusting of the control parameters, e.g. PID-Parameter, was necessary to modify the oscillation to a form with nearly constant displacement level (Fig. 8c). This readjusting led to a rapid increase of the displacement curve as shown in figure 8 at $8.5 \times 10^{6}$ cycles. The continuous increase of the amplitude correlated with a decrease of $\Delta \mathrm{T}$ as a characteristic result of cyclic hardening. The frequency measured by laser vibrometer was constant during the whole test.

The continuous increase of the displacement amplitude prohibited determination of an average value and consequently the calculation of stress amplitude in the gauge length of the AISI 347 specimen was not possible. 

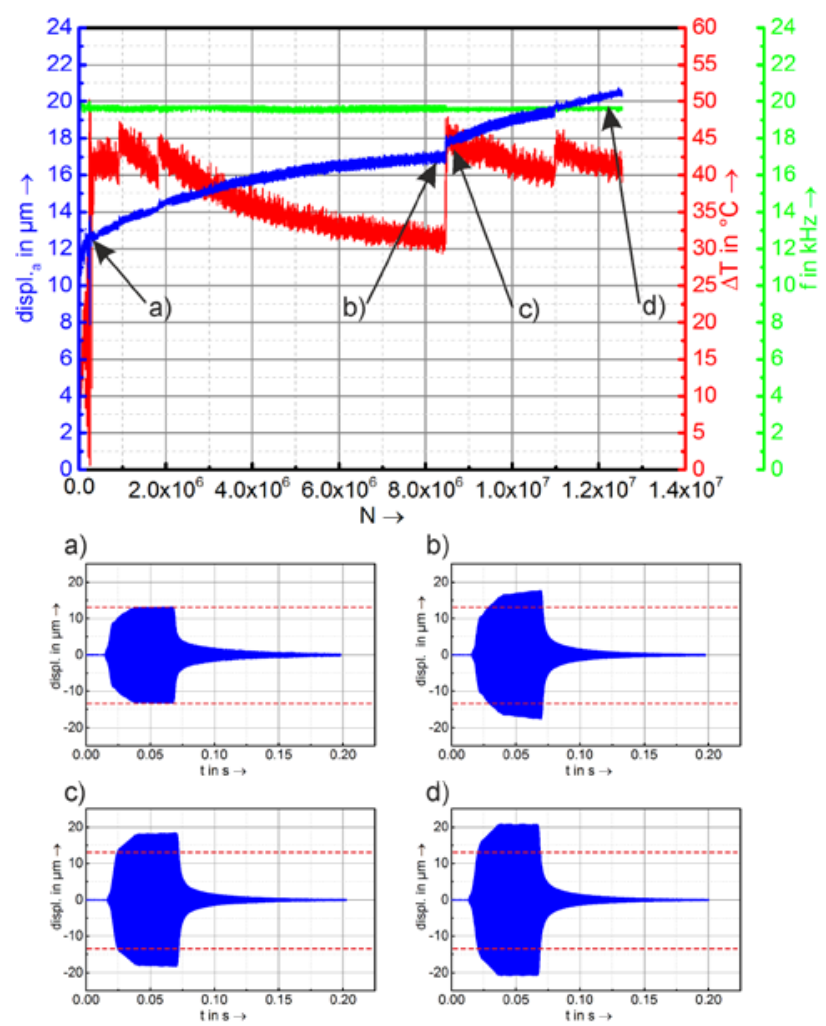

Fig. 8. Displacement amplitude, temperature difference and frequency of AISI 347 during ultrasonic testing without controlling the displacement amplitude

Next the displacement amplitude of the specimen of AISI 347 was controlled from the beginning by readjusting the control parameters to prevent the increasing displacement level during pulses as shown in the test before (comp. Fig. 8b). The control voltage was constant during the fatigue test. By readjusting the control parameters, the increase of the displacement amplitude was kept within acceptable margins from the beginning of the test as shown in figure 9. At the same time, the temperature increase dropped sharply as described for the previous test (see Fig. 8). The fatigue test was interrupted at certain intervals so that the ferromagnetic phase contents could be measured with a Feritscope ${ }^{\mathrm{TM}}$ sensor in the gauge length as an indication of bcc-martensite formation. The bcc-martensite fraction increased as temperature increase during each pulse decreased. The martensitic phase has a bcc crystallographic structure and higher strength than fcc austenite [22], which led to less damping of the oscillation and resulted in higher displacement amplitude. At $4 \times 10^{5}$ cycles, the target displacement amplitude was achieved and stayed constant until the ultimate cycle number of $10^{9}$ was reached.

Further cyclic loading at the target displacement amplitude led to increasing cyclic hardening of the material. The temperature decreased and the bccmartensite content increased. Simultaneously the displacement amplitude rose moderately, so readjusting of the parameters was necessary again at $1.5 \times 10^{6}$ cycles. At this point the pulse-pause ratio was increased to $48 \mathrm{~ms}$ pulse and $8 \mathrm{~s}$ pause in order to reach higher effective frequencies on condition that the maximum temperature of the specimens gauge length would not exceed $50{ }^{\circ} \mathrm{C}$. Another readjusting of the parameters led to an abrupt rise in the $\Delta \mathrm{T}$ course. Further cyclic hardening caused higher $\alpha^{\prime}$-martensite contents which led to further readjusting actions during the test associated with abrupt steps in $\Delta \mathrm{T}$. With increasing bcc martensite transformation the decrease of $\Delta \mathrm{T}$ became flatter and reached a nearly stable level. Further readjusting of the control parameters could now be used to optimize pulse-pause relations to achieve an effective frequency up to more than $\mathrm{f}=1 \mathrm{kHz}$.

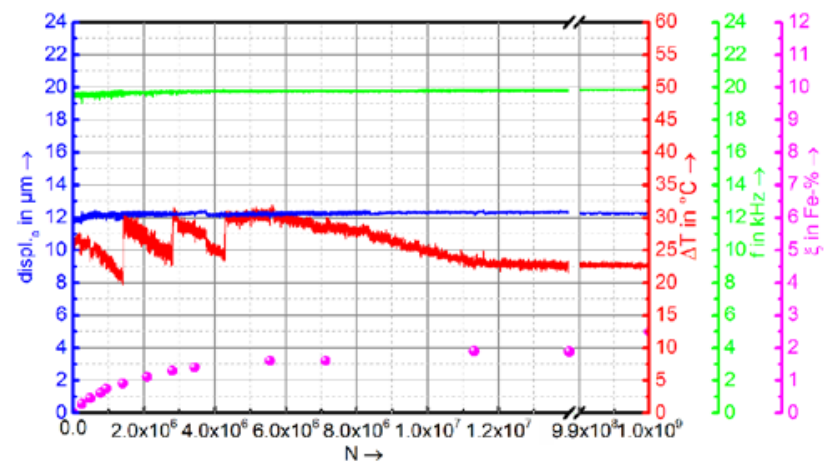

Fig. 9. Displacement amplitude, temperature difference, frequency and $\alpha$ '-martensite development $(\xi)$ of AISI 347 during ultrasonic testing with controlling displacement amplitude

\subsection{VHCF results of cryogenically turned specimens}

In the next step, the cryogenically turned specimens were fatigued at the ultrasonic testing system. The gauge length of the specimens was turned with the parameters as described in chapter 3.1 .

Before testing, Feritscope ${ }^{\mathrm{TM}}$ measurements of the stable austenite AISI 904L indicated $0.0 \mathrm{Fe} \%$. The stress amplitude, calculated according to constant displacement amplitude was $315 \mathrm{MPa}$ for the $\mathrm{SSL}_{\mathrm{p}}$ and $\mathrm{SSL}_{\mathrm{t} 035}$ specimens. Figure 10a) shows the displacement amplitudes of both specimens as well as $\Delta \mathrm{T}$. Whereas the bar representing the conventionally turned and polished specimen with a stable austenitic surface layer $\left(\mathrm{SSL}_{\mathrm{p}}\right)$ is grey, the lifetime of the specimen with a stable surface layer after cryogenic turning $\left(\mathrm{SSL}_{\mathrm{t} 035}\right)$ is shown in red color. The cryogenically turned specimen showed lower self heating than the conventionally turned specimen, although the pulse time was the same because the cyclic hardening characterized by decreasing $\Delta \mathrm{T}$ values was less pronounced in the cryogenically turned specimen, due to the nanocrystalline structure produced by the turning process as shown in Fig 4 . However, fatigue life of the cryogenically turned specimen was distinctly shorter (Fig. 10b) due to the higher roughness of the surface (comp. Fig. 5a and c). 


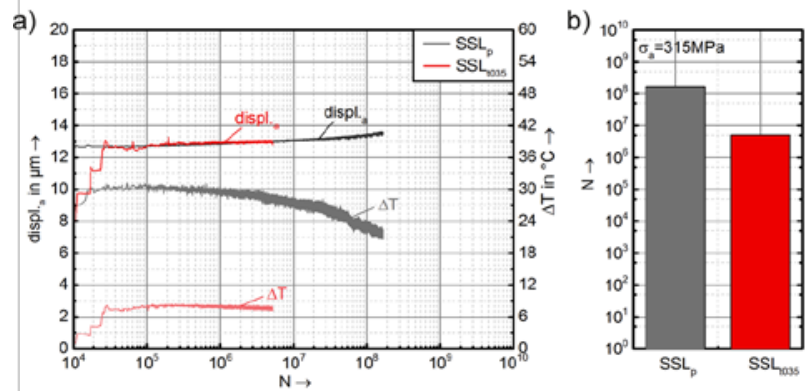

Fig. 10. Displacement amplitude and temperature difference of AISI 904L in $\mathrm{SSL}_{\mathrm{p}}$ and $\mathrm{SSL}_{\mathrm{t} 035}$ state (a) and number of cycles to failure of both states (b)

Scanning electron microscopy fractographs of both specimens are shown in Fig. 11. The mechanism of failure changed from subsurface crack initiation in the $\mathrm{SSL}_{\mathrm{p}}$ specimen to surface crack initiation in the specimen in $\mathrm{SSL}_{\mathrm{t} 035}$ state. The fracture surface of $\mathrm{SSL}_{\mathrm{p}}$ had a fine structured area around the crack initiation site, as shown in the middle of figure $11 \mathrm{a}$ ), whereas $\mathrm{SSL}_{\mathrm{t} 035}$ had the crack initiation from the surface, as shown in figure $11 \mathrm{~b}$ ).
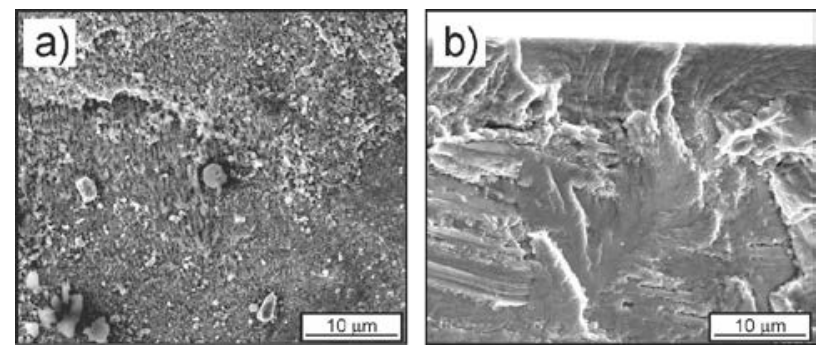

Fig. 11. Scanning electron microscope images of AISI 904L in $\mathrm{SSL}_{\mathrm{p}}$ state (a) and $\mathrm{SSL}_{\mathrm{t} 035}$ state (b)

The metastable austenite AISI 347 was also characterized by Feritscope $\mathrm{TM}^{\mathrm{TM}}$ measurements before fatigue testing. The conventionally turned specimen with austenitic surface layer after polishing $\left(\mathrm{ASL}_{\mathrm{p}}\right)$ did not contain ferromagnetic phases, i.e. $0.0 \mathrm{Fe} \%$ was measured on the surface. The cryogenically turned specimen with a martensitic surface layer after turning $\left(\mathrm{MSL}_{\mathrm{t} 035}\right)$ showed values of $2.8 \mathrm{Fe} \%$ indicated by the Feritscope $^{\mathrm{TM}}$ sensor before testing. The specimen in the $\mathrm{ASL}_{\mathrm{p}}$ state took $1.7 \times 10^{4}$ cycles to achieve the target amplitude as described in chapter 3.2 due to its transient behavior. Subsequently, the amplitude was nearly constant. The steps in temperature were caused by adjusting parameters and optimizing pulse-pause ratio. At $5.7 \times 10^{5}$ load cycles, specimen failure occurred associated with abrupt decreasing $\Delta \mathrm{T}$ and displacement amplitude values due to crack initiation at the surface. The cryogenically turned specimen reached the target displacement amplitude twice as fast as the $\mathrm{ASL}_{\mathrm{p}}$ specimen. Up from this point the amplitude was nearly stable for the rest of the fatigue test. The $\Delta \mathrm{T}$ values were lower at the $\mathrm{MSL}_{\mathrm{t} 035}$ state, because of the nanocrystalline surface layer and the martensitic phase induced by the cryogenic turning process. Because $\Delta \mathrm{T}$ and displacement amplitude were stable until $7 \times 10^{6}$ load cycles and further changes in the test were not expected, the pulse-pause ratio was optimized to raise effective frequency. The resulting development of $\Delta \mathrm{T}$ and displacement amplitude of both specimens are given in figure 12 .
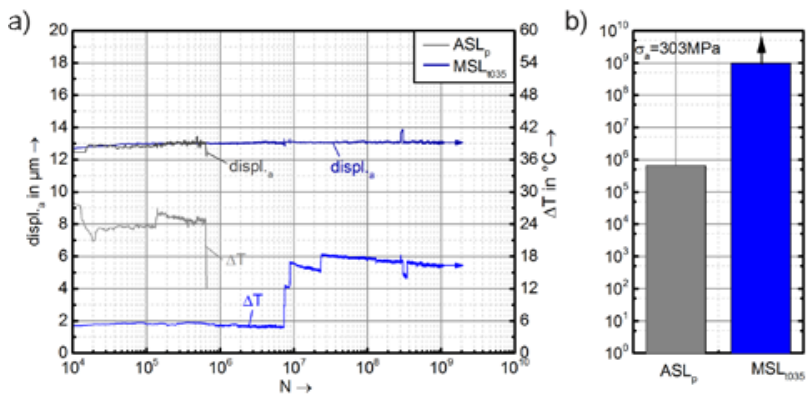

Fig. 12. Displacement amplitude and temperature difference of AISI 347 in $\mathrm{ASL}_{\mathrm{p}}$ and $\mathrm{MSL}_{\mathrm{t} 035}$ state (a) and number of cycles to failure of both states (b)

The cryogenically turned specimen from the metastable AISI 347 reached the ultimate number of cycles without failure contrary to the stable AISI 904L, despite the same roughness on the surface (comp. Fig. 5 $\mathrm{c}$ and $\mathrm{d}$ ). This suggests that the $\alpha^{\prime}$-martensite phase in the surface layer overcompensates the detrimental effect of high roughness and leads to longer specimen lifetime. The $\alpha$-martensitic content of the cryogenically turned specimen was stable during the whole test at $2.8 \mathrm{Fe} \%$.

Scanning electron microscope investigations of the fracture surface of the $\mathrm{ASL}_{\mathrm{p}}$ specimen are shown in Figure 13. Crack initiation is starting at the surface of the specimen, which is typical for a failure at cycle numbers up to $10^{6}$.

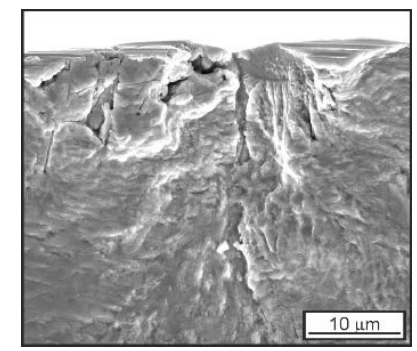

Fig. 13. Scanning electron microscope image of AISI 347 in $\mathrm{ASL}_{\mathrm{p}}$ state

\section{Conclusion}

The present work investigates the very high cycle fatigue (VHCF) behavior of a stable and a metastable austenitic $\mathrm{Cr}-\mathrm{Ni}$ steel on ultrasonic testing systems with a frequency of $\mathrm{f}=20 \mathrm{kHz}$ as well as the influence of surface morphology on fatigue behavior produced by a cryogenic turning process compared to conventionally turned and subsequently polished specimens. Both materials consisted of pure austenitic structure at the as received state confirmed by SEM/EBSD and Feritscope ${ }^{\mathrm{TM}}$ measurements. The stable AISI 904L showed low cyclic hardening during fatigue testing and thus a slight increase of displacement amplitude. At $1.66 \times 10^{8}$ cycles, specimen failure occurred from subsurface crack initiation. Even after failure no bcc martensite could be detected. 
In contrast to that, the metastable AISI 347 specimens did show a pronounced increase of displacement amplitude during testing without adjusting parameters due to their transient behaviour which also causes a remarkable decrease of the specimen selfheating during each load pulse $\Delta \mathrm{T}$. The cyclic hardening indicated by decreasing $\Delta \mathrm{T}$ correlated in metastable austenites with the formation of deformation induced $\alpha^{\prime}$ martensite. The ferromagnetic bcc-martensite was confirmed with Feritscope ${ }^{\mathrm{TM}}$ measurements. Without intervention, i.e. regular readjusting control parameters, no single step test at AISI 347 was possible with the ultrasonic testing system. To realize fatigue tests at constant displacement amplitudes, the parameters were readjusted until a nearly stable state of the material was achieved.

The influence of cryogenic turning on VHCF behavior of stable AISI 904L and metastable AISI 347 steel was investigated. The cryogenically turned specimens were fatigued at the same displacement amplitude as their polished counterparts with the same pulse pause ratios to compare the results. FIB cuts show the machining induced changes in microstructure under the surface, with a nanocrystalline layer formed in the cryogenic turning process. The cryogenically turned specimen of AISI 904L as well as that of AISI 347 showed lower self heating during the load pulses compared to their polished counterparts. Furthermore, the AISI 904L specimen achieved a lower number of cycles to failure in the cryogenically turned state due to higher surface roughness resulting from the turning process. In contrast to that, the cryogenically turned specimen of AISI 347 achieved the ultimate number of cycles of $10^{9}$ in spite of higher roughness than their polished counterpart which failed at $6.4 \times 10^{6}$ cycles under the same loading conditions. This leads to the conclusion that the influence of bcc $\alpha^{\prime}$-martensite induced by cryogenic turning overcompensates the detrimental effects of roughness and leads to a higher lifetime of the metastable austenitic specimen.

The authors thank and are grateful for the support of the German Research Foundation (DFG) within the CRC926 Microscale Morphology of Component Surface, and the Nanostructuring Center (NSC) of the University of Kaiserslautern for performing the FIB-investigations. The cryogenically turned specimens were turned at the Institute for Manufacturing Technology and Production Systems. The authors thank Prof. J.C. Aurich as well as H. Hotz for their support. We also thank Prof. J. Seewig, that we could perform the confocal microscopy investigations at the Institute for Measurement and Sensor-Technology.

\section{References}

1. C. Bathias, Fatigue Fract. Eng. Mater. Struct. 22, 559-565 (1999)

2. H. Mughrabi, Fatigue Fract. Eng. Mater. Struct. 25, 755-764 (2002)

3. H. Mughrabi, Int. J. Fatigue 28, 1501-1508 (2006)
4. R. Skorupski, M. Smaga, D. Eifler, Adv. Mat. Res. 891-892, 464-469 (2014)

5. M. Smaga, R. Skorupski, P. Mayer, B. Kirsch, J. C. Aurich, I. Raid, J. Seewig, J. Man, D. Eifler, T. Beck, Procedia Structural Integrity 5, 989-996 (ScienceDirect, Funchal, 2017)

6. A.M. Eleiche, M.M. Megahed, N.M. Abd-Allah, J. Mater. Process. Technol. 113, 502-508 (2001)

7. R. K. Nalla, I. Altenberger, U. Noster, G. Y. Liu, B. Scholtes, R. O. Ritchie, Mater. Sci. Eng. A 355, 216-230 (2003)

8. T. Klotz, D. Delbergue, P. Bocher, M. Lévesque, M. Brochu, Int. J. Fatigue 110, 10-21 (2018)

9. I. Altenberger, B. Scholtes, U. Martin, H. Oettel, Mater. Sci. Eng. A 264, 1-16 (1999)

10. C. Ye, S. Suslov, D. Lin, G. J. Cheng, Philos. Mag. 92, 1369-1389 (2012)

11. M. Smaga, A. Sorich, D. Eifler, T. Beck, VHCF7 Seventh International Conference on Very High Cycle Fatigue, Siegener werkstoffkundliche Berichte 14, 249-254 (Dresden, 2017)

12. K. Takahashi, T. Ogawa, Journal of Solid Mechanics and Materials Engineering 2, 366-373 (2008)

13. T. Naoe, Z. Xiong, M. Futakawa, J. Nucl. Mater. 468, 331-338 (2016)

14. J. V. Carstensen, H. Mayer, P. Brønsted, Fatigue Fract. Eng. Mater. Struct. 25, 837-844 (2002)

15. A. C. Grigorescu, P. M. Hilgendorff, M. Zimmermann, C. P. Fritzen, H. J. Christ, Int. J. Fatigue 93, Part 2, 250-260 (2016)

16. C. Müller-Bollenhagen, M. Zimmermann, H. J. Christ, Procedia Eng. 2, 1663-1672 (2010)

17. T. Angel, Journal of the Iron and Steel Institute, 177, 165-174 (1954)

18. G. H. Eichelmann, T. C. Hull, Trans. Am. Soc. Met. 45, 77-104 (1953)

19. P. Mayer, R. Skorupski, M. Smaga, D. Eifler, J. C. Aurich, Proc. CIRP 14, 101-106 (2014)

20. J. Talonen, P. Aspegren, H. Hanninen, Mater. Sci. Technol. 20, 1506-1512 (2004)

21. J. C. Aurich, P. Mayer, B. Kirsch, D. Eifler, M. Smaga, R. Skorupski, CIRP Ann. - Manuf. Techn. 63, 65-68 (2014)

22. M. Smaga, R. Skorupski, D. Eifler, T. Beck, J. Mater. Res. 32, 4452-4460 (2017) 